\title{
Nascentes Urbanas de Goioerê: diagnóstico ambiental
}

\author{
Goioere Urban Springs: environmental diagnosis
}

Nacientes Urbanas de Goioerê: diagnóstico ambiental

\author{
Vania Negri-Sakata ${ }^{1}$ \\ Irene Yukiko Kimura ${ }^{2}$
}

\begin{abstract}
RESUMO: As nascentes urbanas tiveram seu ambiente ocupado ou degradado, devido ao advento do processo de urbanização no Brasil, sem considerar a sua importância para o abastecimento de água na superfície e no funcionamento do ciclo hidrológico. O objetivo desta pesquisa foi diagnosticar a situação ambiental das nascentes urbanas de Goioerê, PR, verificando se o contexto ambiental condiz com a legislação em vigor. $O$ estudo foi realizado por meio de levantamento de dados em órgãos públicos, pesquisas em livros, artigos e leis, e também visita in loco para observação e avaliação da condição de conservação das nascentes. Foram mapeadas e avaliadas nove nascentes, sendo que uma foi considerada em bom Grau de Preservação (GP), mas com ausência de vegetação necessária para estar em total conformidade com a legislação; as demais apresentavam diversos problemas que as impediam de ser classificada em melhores índices, três ficaram classificadas em GP regular, duas ruim e três péssimo. Portanto, conclui-se que essas nascentes urbanas estão sofrendo impactos ambientais de ordem antrópica e estão em desacordo com a legislação, necessitando de ações de preservação, que sejam efetivadas de forma contínua por meio da interação das entidades públicas e a população local.
\end{abstract}

PALAVRAS-CHAVE: Impactos ambientais. Legislação. Preservação.

ABSTRACT: The urban springs had their environment occupied or degraded, because of the advent of the process of urbanization in Brazil, without taking into account its importance for surface water supply and the functioning of the hydrological cycle. The objective of this work was to diagnose the current situation of the urban springs of the city of Goioerê, Parana and to verify whether the condition of the environment is in accordance with current legislation. The study was completed through data collection from public agencies, research in books, articles and laws and visiting sites for observation and evaluation of the springs. Nine springs were mapped and evaluated and only one was considered to be good within the Preservation Degree (PD), but with no vegetation needed to be fully compliant with the legislation; the others had several problems that prevented them from being classified in the

\footnotetext{
1 Licenciada em Geografia, Mestranda em Ensino de Ciências Ambientais, Universidade Estadual de Maringá, Campus Regional de Goioerê, Avenida Reitor Zeferino Vaz, s/n, Jardim Universitário, 87360-000, Goioerê, Paraná. E-mail: vania.negri@hotmail.com.

2 Licenciada e Bacharel em Química, Doutora em Química Analítica, Universidade Federal de Santa Catarina, Universidade Estadual de Maringá, Campus Regional de Goioerê, Avenida Reitor Zeferino Vaz, s/n, Jardim Universitário, 87360-000, Goioerê, Paraná. E-mail: iykimura@gmail.com.
} 
best indices, three were classified in regular PD, two bad, and three very bad. Therefore, it was concluded that these urban springs are suffering environmental impacts of anthropic order and are in disagreement with the legislation, needing effective preservation actions supported by continuous interaction with public entities and the local population.

KEY WORDS: Environmental impacts. Legislation. Preservation.

RESUMEN: Las nacientes urbanas tuvieron su ambiente ocupado o degradado, debido a la llegada del proceso de urbanización en Brasil, sin considerar su importancia para el abastecimiento de agua en la superficie y en el funcionamiento del ciclo hidrológico. El objetivo de esta investigación fue diagnosticar la situación ambiental de las nacientes urbanas de Goioerê, PR, analizando si el contexto ambiental se pone de acuerdo con la Legislación en vigor. En un total de nueve nacientes fueron mapeadas y evaluadas, siendo que una fue considerada en buen Grado de Preservación, pero con ausencia de vegetación necesaria para estar en total conformidad con la legislación; las demás presentaban diversos problemas que las impedían de ser clasificadas con mejores índices, tres quedaron clasificadas en GP regular, dos como malo y tres como pésimo. Por lo tanto, se concluye que esas nacientes urbanas están sufriendo impactos ambientales de orden antrópico y están en desacuerdo con la legislación, necesitando acciones de preservación, que se efectúen de modo continuo por medio de la interacción de las entidades públicas y la población local.

PALABRAS-CLAVE: Impactos ambientales. Legislación. Preservación.

\section{INTRODUÇÃO}

Estudos referentes aos recursos hídricos são cada vez mais necessários na tentativa de buscar compreensão e alternativas para preservar esse recurso natural essencial ao equilíbrio do meio ambiente. $O$ aumento da demanda pelos recursos hídricos tem gerado conflitos de utilização em várias regiões do país e, além disso, houve progressiva degradação da qualidade das águas em virtude da intensificação das atividades industriais, agropecuárias e de mineração. Assim, mesmo em situações em que não há restrições de natureza quantitativa, a degradação da qualidade da água inviabiliza o seu uso para fins mais nobres. Essa é a situação nos grandes centros urbanos brasileiros em diferentes regiões do país (ANA, 2017).

Porto-Gonçalves (2007) explica que nas grandes aglomerações humanas a água é imprescindível tanto para as diversas atividades que nela se desenvolvem como para o abastecimento de suas populações. A água difere dos outros minerais, pois ela é insubstituível. Se olharmos a distribuição geográfica da humanidade no globo, nota-se que é em torno dos rios, lagos, oásis ou litoral, sobretudo próximo às desembocaduras de rios, que estão as maiores densidades demográficas.

Entretanto, Tucci (2010) ressalta que, com um elevado número de pessoas vivendo em um local restrito, a urbanização aumenta as áreas impermeáveis e a canalização da água, aumenta os picos de cheia, também aumenta a velocidade da água e a produção de 
sedimentos e dos resíduos sólidos que escoam para a drenagem, tudo isso aliado à falta de serviços de limpeza e manutenção. Estes sólidos reduzem a capacidade de escoamento e aumenta a poluição, devido à lavagem das impurezas das superfícies urbanas tal como a grande quantidade de metais, interferindo na qualidade das águas superficiais e nascentes.

A água é um recurso renovável clássico, que irá circular continuamente, independentemente de idade do gelo e aquecimento global (ROGERS; LLAMAS; MARTÍNEZ-CORTINA, 2006). No ciclo hidrológico a água é continuamente reciclada através da atmosfera, dos oceanos para os continentes e retorna para os oceanos. Esse processo é possível pela ação da radiação solar e pela facilidade d'água passar do estado líquido para o gasoso sob as condições da superfície (WINCANDER; MONROE, 2011). Da precipitação que cai sobre os continentes, a maior parte fica temporariamente retida no solo próximo de onde caiu e finalmente retorna à atmosfera na forma de vapor d'água através da evapotranspiração. Uma parte da água restante escoa sobre a superfície do solo ou através deste para os rios, enquanto outra parte penetra profundamente no solo e suprirá o lençol d'água subterrâneo (ANA, 2014). Assim o ciclo da água é responsável pela renovação das águas e a água da chuva que infiltra no solo abastece os aquíferos que se acumula em função de estar sobre uma camada impermeável. Quando ocorre o afloramento da camada impermeável ou do lençol freático surgem as nascentes (PARANÁ, 2010).

As nascentes, objeto deste estudo, apresentam alto valor para o abastecimento hídrico superficial. Segundo Felippe (2009) elas são sistemas de importância primeira para a manutenção do equilíbrio hidrológico e ambiental lato sensu das bacias hidrográficas. Hirata, Zoby e Oliveira (2010) também descreve que as nascentes carecem de proteção, as zonas de afloramento de águas subterrâneas são vulneráveis à contaminação do aquífero, de forma que deve promover a sensibilização do uso do solo nessa região.

As fontes ou nascentes sempre encantaram as pessoas, muitos as veem como detentoras de poderes místicos e de cura. Embora possam ocorrer sob uma grande variedade de condições geológicas, todas se formam basicamente da mesma maneira, isto é, quando a água que se infiltrou no solo chega ao lençol freático ou em uma camada impermeável, intercepta a superfície e essa água é descarregada através de uma fonte (WINCANDER; MOROE, 2011).

Para evitar consequências maiores é de suma importância respeitar as leis específicas para as nascentes. Desde 1965, a lei que protege as nascentes é a Lei $n^{\circ} 4.771$ de 15 de setembro de 1965 , e no seu Art. $2^{\circ}$ consideram-se de preservação permanente as florestas e demais formas de vegetação natural situadas: "[...] nas nascentes, ainda que intermitentes e nos chamados 'olhos d'água', qualquer que seja a sua situação topográfica, num raio mínimo de 50 (cinquenta) metros de largura" (BRASIL, 1965). Essa lei foi alterada pela Lei 
7.803/1989 e a Medida Provisória no 2.166-67 de 24 de agosto de 2001, "Consideram-se de preservação permanente, pelo efeito de Lei, as áreas situadas nas nascentes, ainda que intermitentes e nos chamados 'olhos d'água', qualquer que seja a sua situação topográfica, devendo ter um raio mínimo de 50 (cinquenta) metros de largura". Segundo o Artigo 3. ${ }^{\circ}$ dessa lei "A área protegida pode ser coberta ou não por vegetação nativa, com a função ambiental de preservar os recursos hídricos, a paisagem, a estabilidade geológica, a biodiversidade, o fluxo gênico de fauna e flora, proteger o solo e assegurar o bem-estar das populações humanas".

A Resolução Conama no 429 de 28 de fevereiro de 2011 dispõe sobre a metodologia de recuperação das áreas de preservação permanente, e versa sobre os aspectos da vegetação e adoção de medidas de prevenção e proteção dessa área (BRASIL, 2011). E o Código Florestal Brasileiro Lei oㅜ 12.651 de 25 de maio de 2012, Art. 4ํe e capítulo IV considera Área de Preservação Permanente o entorno de olhos d'água perenes, num raio de 50 metros, qualquer que seja sua situação topográfica.

A proteção de nascentes brasileiras também é influenciada pelo avanço na gestão das águas, está garantida pela Lei das Águas, pois a água tem múltiplo uso e função e sua gestão deverá ocorrer de maneira descentralizada, contando com a participação do poder público, comunidade e usuários. Essa lei foi promulgada em 8 de janeiro de 1997 pela Lei no 9.433 e apresenta fundamentos, objetivos e diretrizes gerais de ação para implementação da Política Nacional de Recursos Hídricos em nosso território (BRASIL, 1997).

$\mathrm{Na}$ urbe de São Paulo, os rios foram canalizados ou drenados e devido à crise hídrica da cidade, atualmente está cada vez mais presente a preocupação em recuperar as nascentes urbanas. Yamato, Parma e Schutzer (2014, p. 3) propõem a "[...] renaturalização de nascentes - seus anfiteatros e altos cursos de córregos - no contexto dos projetos de requalificação urbana vinculados ao adensamento construtivo nas áreas intensamente urbanizadas [...]".

A preocupação com as nascentes tem fomentado a criação de vários programas de proteção e recuperação de nascentes no Brasil como, por exemplo, o Programa Produtor de Água, o qual usa o conceito Pagamento por Serviços Ambientais - PSA (ANA, 2012), Programa Nacional de Proteção de Nascentes do Serviço Nacional de Aprendizagem Rural (2015), Programa Plantadores de Rios (BRASIL, 2017) e no Estado do Paraná há o programa Nascentes Protegidas e Recuperadas (PARANÁ, 2010). Esses são apenas alguns dos vários programas de proteção de nascentes, nos quais se percebe a existência de uma consciência sobre a importância de preservação das nascentes, porém ainda são poucos os programas destinados exclusivamente às nascentes urbanas.

O tema dessa pesquisa foi escolhido devido à existência de pouca literatura relacionada às nascentes urbanas em Goioerê - PR e pela amplitude da importância hídrica 
na natureza e para a sociedade, havendo a necessidade do levantamento de dados sobre esses mananciais para procurar meios de melhor preservá-los. Portanto, o objetivo deste estudo foi diagnosticar a situação ambiental em que se encontra as nascentes urbanas de Goioerê, PR, verificando se o contexto ambiental condiz com a legislação em vigor.

\section{METODOLOGIA}

\section{Caracterização da Área de Estudo}

O estudo foi realizado na área urbana de Goioerê - PR, que é uma cidade de porte pequeno, localizada no noroeste do Estado do Paraná. Sua posição geográfica é 2411' 05" Latitude S, 530 01' 39" Longitude W e altitude de 505 metros (INSTITUTO PARANAENSE DE DESENVOLVIMENTO ECONÔMICO E SOCIAL, 2017). A figura 1 ilustra a localização urbana do município de Goioerê, no contexto nacional, estadual e municipal.

Figura 1 - Área urbana de Goioerê, PR

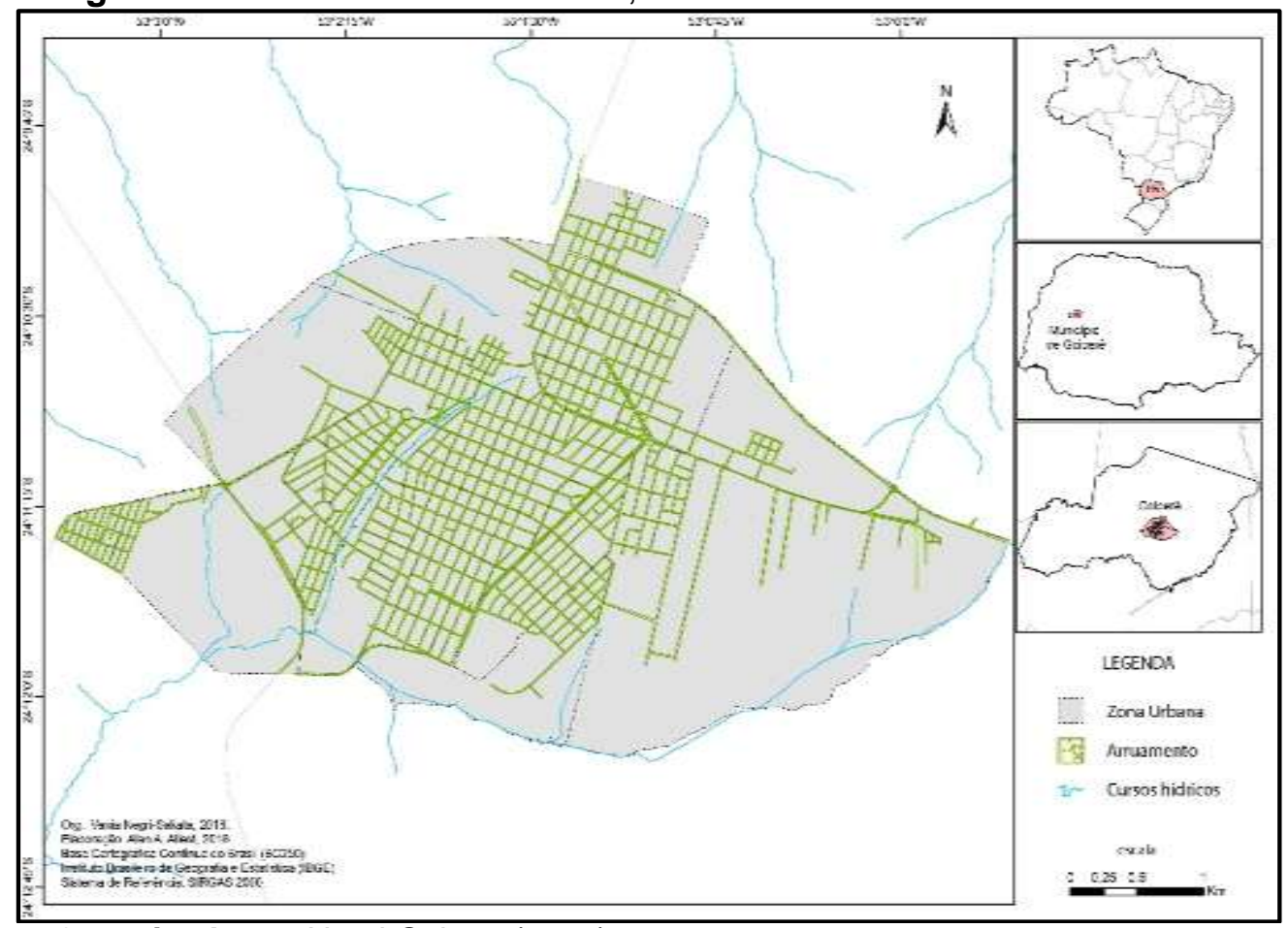

Organizado por Negri-Sakata (2018).

O município apresenta aproximadamente 29.500 habitantes, sendo que mais de $85 \%$ da população reside no espaço urbano (IBGE, 2017). A cidade é abastecida de água pela Companhia Paranaense de Águas (Sanepar), que capta as águas do Aquífero Serra Geral, a partir de quatro poços artesianos. Nessa região há abundância de precipitações pluviométricas, sendo a média dos últimos 10 anos de aproximadamente 1.793 
milímetros/ano (ÁGUASPARANÁ, 2017). O relevo apresenta-se ondulado a levemente ondulado, em declividade constante no sentido nordeste-sudeste, e toda a bacia do município deságua no Rio Piquiri. O solo é constituído por pequena predominância de latossolo vermelho escuro distrófico, texturas argilos mistos, argiloso arenoso e ainda areno argiloso. O clima é subtropical úmido mesotérmico, com verões quentes e geadas poucos frequentes, com a tendência de concentração das chuvas nos meses de verão. A média das temperaturas nos meses mais quentes é em torno de 29 graus Celsius $\left({ }^{\circ} \mathrm{C}\right)$ e nos meses mais frios é inferior a $12{ }^{\circ} \mathrm{C}$. O perímetro urbano de cidade de Goioerê contém o Rio Água Bela e o Arroio Schimidt, os quais pertencem à Bacia do Rio Piquiri (IBGE, 2017).

\section{PROCEDIMENTOS METODOLÓGICOS}

A pesquisa foi de cunho qualitativo, com análise das informações de forma sistêmica e qualitativa. A pesquisa bibliográfica se baseou em artigos, livros e sites, entre outros, e para a localização das nascentes foram realizadas coletas de informações cedidas pela prefeitura, Sanepar e por alguns dos moradores residentes na sua proximidade. As coletas de dados foram realizadas durante os meses de junho e julho de 2017, e nesse estudo foram contempladas nove nascentes de maiores visibilidades, porém há evidência da existência de outras nascentes urbanas. Na análise da situação ambiental de cada nascente e de seu entorno foram realizadas visitas in loco para observação e mensuradas as coordenadas geográficas com aparelho GPS marca Garmin e modelo Etrex - Vista. Após a coleta de dados e estudos dos impactos ambientais nas nascentes os parâmetros macroscópicos foram enquadrados em padrões para a quantificação e utilizou-se o quadro de Classificação de Grau de Impacto de Nascente, proposto por Gomes, Melo e Vale (2005). E este método de diagnóstico ambiental de nascentes foi escolhido por ser de fácil aplicação e compreensão e fornecer resultados satisfatórios.

Os parâmetros para análise da qualidade ambiental das nascentes foram baseados na metodologia proposta por Gomes, Melo e Vale (2005) que, por meio de uma análise visual e sensorial, detecta a cor aparente da água, odor, presença de resíduos sólidos ao redor, materiais flutuantes, espuma, óleo, vegetação, uso por animais, uso por humanos, local de proteção, proximidade residencial ou estabelecimento e tipo de área de inserção, fatores considerados determinantes para a avaliação da qualidade ambiental da nascente. Cada um desses itens possui um valor que é transformado em padrão de qualidade, conforme Quadro 1. O Índice de Impacto Ambiental em Nascentes (IIAN) distribui as nascentes em classes conforme seu Grau de Preservação (GP) (Quadro 2).

O conceito de impacto ambiental utilizado é o da Resolução Conama no 001 de 23 de janeiro de 1986, que no artigo $1^{\circ}$ considera impacto ambiental qualquer alteração das 
propriedades físicas, químicas e biológicas do meio ambiente, causada por qualquer forma de ações humanas que possam, direta ou indiretamente, afetar a saúde, a segurança e o bem-estar da população, as atividades sociais e econômicas, a biota, as condições estéticas e sanitárias do meio ambiente, e a qualidade dos recursos ambientais (BRASIL, 1986).

Quadro 1 - Quantificação da análise dos parâmetros macroscópicos para análise da qualidade ambiental de nascentes

\begin{tabular}{|c|c|c|c|}
\hline Cor da água & (1) Escura & (2) Clara & (3) Transparente \\
\hline Odor & (1) Cheiro forte & (2) Cheiro fraco & (3) Sem cheiro \\
\hline $\begin{array}{l}\text { Resíduos sólidos ao } \\
\text { redor }\end{array}$ & (1) Muito & (2) Pouco & $\begin{array}{l}\text { (3) Sem resíduos } \\
\text { sólidos ao redor }\end{array}$ \\
\hline Materiais flutuantes & (1) Muito & (2) Pouco & $\begin{array}{ll}\text { (3) Sem } & \text { Materiais } \\
\text { flutuantes }\end{array}$ \\
\hline Espuma & (1) Muita & (2) Pouca & (3) Sem espuma \\
\hline Óleo & (1) Muito & (2) Pouco & (3) Sem óleo \\
\hline Esgoto & (1) Doméstico & (2) Fluxo Superficial & (3) Sem esgoto \\
\hline Vegetação & (1) Alta degradação & (2) Baixa degradação & (3) Preservada \\
\hline Uso por animais & (1) Presença & (2) Apenas marcas & (3) Ausência \\
\hline Uso por humanos & (1) Presença & (2) Apenas marcas & (3) Ausência \\
\hline Proteção do local & (1) Sem proteção & $\begin{array}{l}\text { (2) Com proteção } \\
\text { (acessível) }\end{array}$ & $\begin{array}{l}\text { (3) Com proteção (sem } \\
\text { acesso) }\end{array}$ \\
\hline $\begin{array}{l}\text { Proximidade com } \\
\text { residência ou } \\
\text { estabelecimento }\end{array}$ & $\begin{array}{c}\text { (1) Menos } \\
\text { metros }\end{array}$ de 50 & $\begin{array}{l}\text { (2) Entre } 50 \text { a } 100 \\
\text { metros }\end{array}$ & (3) Acima de 100 metros \\
\hline $\begin{array}{l}\text { Tipo de área de } \\
\text { inserção }\end{array}$ & (1) Ausente & $\begin{array}{l}\text { (2) Propriedade } \\
\text { privada }\end{array}$ & $\begin{array}{l}\text { (3) Parques ou áreas } \\
\text { protegidas }\end{array}$ \\
\hline
\end{tabular}

Adaptado de Gomes, Melo e Vale (2005).

Quadro 2 - Classificação das nascentes quanto ao grau de preservação

\begin{tabular}{|c|c|c|}
\hline Classe & Grau de Preservação (GP) & Pontuação Final \\
\hline A & Ótima & 37 a 39 pontos \\
\hline B & Boa & 34 a 36 pontos \\
\hline C & Razoável & 31 a 33 pontos \\
\hline D & Ruim & 28 a 30 pontos \\
\hline E & Péssima & Abaixo de 28 pontos \\
\hline
\end{tabular}

Adaptado de Gomes, Melo e Vale (2005).

\section{RESULTADOS E DISCUSSÕES}

As nove nascentes identificadas foram denominadas: nascente Parque Municipal Danilo Marques Moura (NG1); nascente Parque do Povo (NG2), nascente Colina Verde (NG3), nascente Porto das Águas (NG4), nascente Arroio Schimidt (NG5-A), nascente Jardim Galileia (NG5-B), nascente Vila Guaíra (NG6), nascente da ASSEMUG (NG7) e nascente Jardim Bela Vista (NG8). A figura 2 mostra a localização das nascentes urbanas de Goioerê, PR.

$\mathrm{Na}$ sequência foi localizada cada uma das nascentes e as suas coordenadas geográficas. Também foram realizadas avaliações e discussões dos resultados obtidos da 
situação ambiental de cada nascente pesquisada, baseadas nos Quadros 1 e 2 de quantificação da análise dos parâmetros macroscópicos para análise da qualidade ambiental de nascentes e de classificação quanto ao grau de preservação (GP), respectivamente.

Figura 2 - Nascentes urbanas de Goioerê, PR

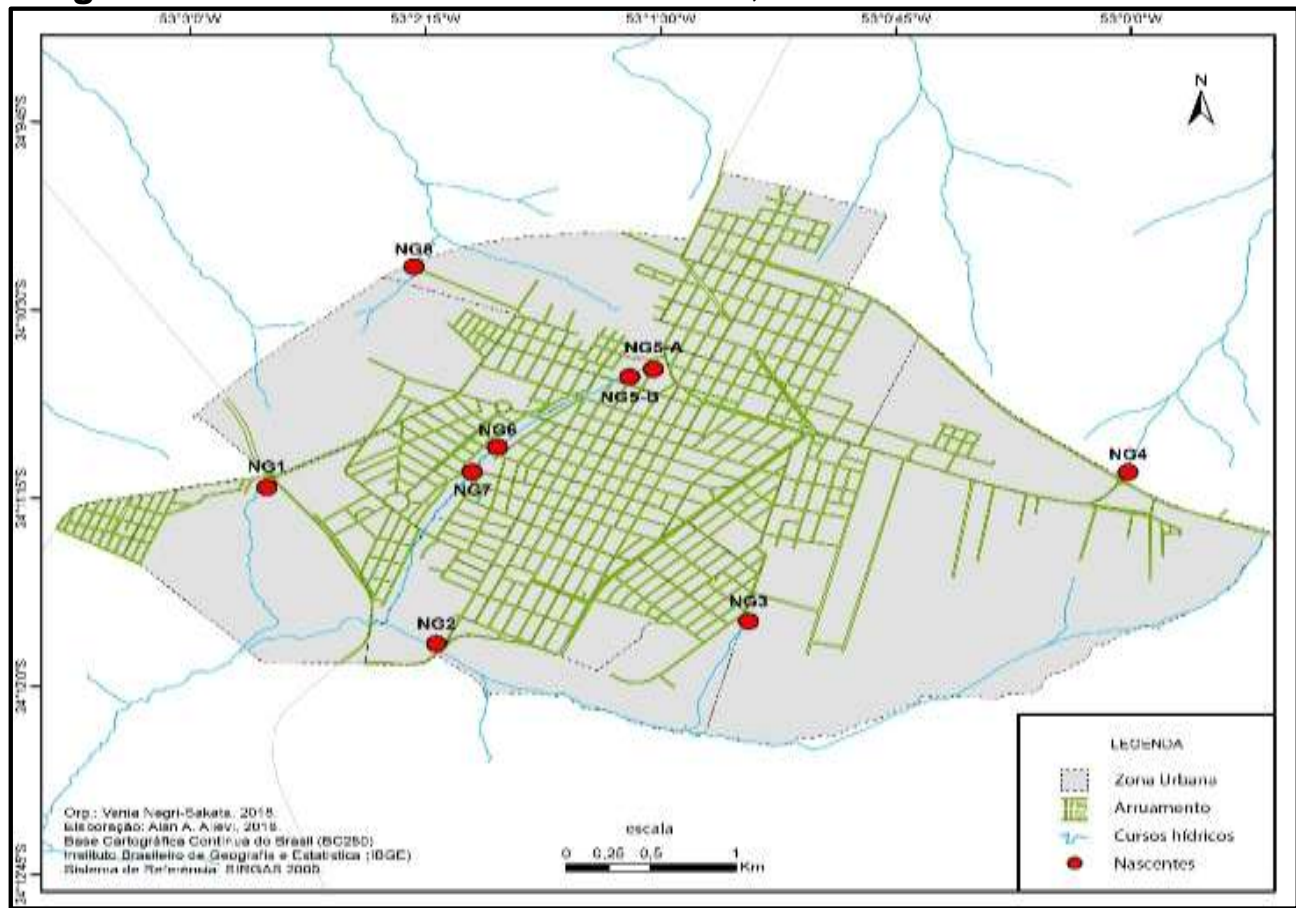

Organizado por Negri-Sakata (2018).

\section{Nascente Parque Municipal Danilo Marques Moura (NG1)}

A NG1 está localizada no Parque Municipal Danilo Marques Moura, na Avenida Zeferino Vaz, sem número, próximo à rodovia PR 180, nas coordenadas geográficas: $24^{0}$ $11^{\prime} 15^{\prime \prime}$ Latitude $S, 53^{\circ} 02^{\prime} 45^{\prime \prime}$ Longitude W e a 442 metros de altitude. A NG1 se encontra inserida em uma Unidade de Conservação (UC) do município de Goioerê. De acordo com Carard (2016) há outras nascentes temporárias e permanentes no interior dessa UC, sendo que a NG1 é do tipo perene e difusa, sem acúmulo de água. Suas águas escoam no córrego "sem nominação" que é afluente do Rio Água Bela.

A água da NG1 apresentou-se com a cor clara, sem odor perceptível, com ausência de resíduos sólidos, materiais flutuantes, espuma, óleo e esgoto. Também não há evidências de uso por animais domésticos ou humanos e nem há proteção local ou moradia num raio de 150 metros. Portanto, 76,9\% das características avaliadas e verificadas, conforme os parâmetros indicados no Quadro 3, indicam que a NG1 se encontra em bom nível de preservação (GP Boa). Porém, a leste da NG1, a vegetação se encontra em nível de baixa degradação, pois não há arborização, além disso, está próximo ao limite entre o 
parque e a propriedade privada, a qual está recoberta por gramíneas e em desacordo com a Lei n. 12.651/2012 do Código Florestal Brasileiro (BRASIL, 2012), necessitando de reflorestamento da área degradada, o qual contribuirá para elevar o nível de preservação. $A$ figura 3 (A) ilustra a Nascente Parque Municipal Danilo Marques Moura (NG1) e a seta vermelha indicam o seu ponto de afloramento.

\section{Nascente Parque do Povo (NG2)}

A nascente Parque do Povo (NG2) está contida no Parque do Povo, o qual está localizado na Avenida Vicente Carlos, saída para a PR 180. O Parque do Povo é uma área de lazer com infraestrutura que se destina às práticas esportivas tais como pista de caminhada, campo de futebol, bocha e quadra poliesportiva. A NG2 está localizada nas coordenadas geográficas: $24^{0} 11^{\prime} 43^{\prime \prime}$ Latitude $S, 53^{\circ} 02^{\prime} 16^{\prime \prime}$ Longitude W e a 431 metros de altitude, também se encontra contida na Área de Preservação Permanente (APP) do Rio Água Bela. A NG2 é do tipo perene, de depressão e pontual, e suas águas escoam para o Rio Água Bela.

A água da NG2 apresentou-se com a cor clara, sem odor, contudo ao redor da mesma foram percebidos resíduos sólidos (guarda-chuva, sacola e garrafa plástica) e materiais flutuantes, e notou-se ausência de espuma, óleo e esgoto. A vegetação existente em torno da NG2 é a gramínea. A NG2 está próxima da pista de caminhada e diariamente os humanos e os animais (equinos e cachorros) estão presentes. Aproximadamente a 100 metros da NG2 está localizado o prédio do salão de eventos do parque e construções residenciais do bairro Santa Casa. Foi observado, ao analisar as características da NG2 no Quadro 3, que a maioria dos parâmetros macroscópicos pode melhorar o seu nível de qualidade (GP Ruim), desde que os órgãos públicos providenciem a recuperação e a proteção local, impedindo a proximidade e a circulação de humanos e animais, e que seja arborizada no seu entorno. A figura 3 (B) mostra a Nascente Parque do Povo (NG2) e a seta vermelha indica o ponto de afloramento.

\section{Nascente Colina Verde (NG3)}

A nascente Colina Verde (NG3) está localizada em uma região suburbana, limítrofe entre o Bairro Colina Verde e a zona rural. Está localizada nas coordenadas geográficas: $24^{0} 11^{\prime} 43^{\prime \prime}$ Latitude S, $53^{\circ} 01^{\prime} 13^{\prime \prime}$ Longitude W e a 452 metros de altitude.

A NG3 é do tipo difusa e de depressão, e suas águas escoam para o Rio Água Bela. Ela já foi utilizada pela Sanepar para abastecimento público, porém em 2013 foi desativada, 
por motivos operacionais e inviabilidade econômica, pois a captação da água do aquífero Serra Geral, por meio de poços artesianos, indicou maior eficiência e redução de custos e serviços de manutenção. No entanto, ainda se encontram no local as três caixas de concreto onde eram os pontos do sistema de captação de água.

A água da NG3 apresentou-se na cor clara, sem odor, porém havia resíduos sólidos (sofá, sacolas e garrafa plástica) em seu entorno, e ausência de materiais flutuantes, espuma, óleo e esgoto. A vegetação apresentou um baixo nível de degradação, pois a área é arborizada com mais de 50 metros no seu entorno, exceto ao sul onde há uma estrada rural. Não foi observada na NG3 a presença ou a sua utilização por animais, porém a quantidade de resíduos sólidos existentes e a proximidade da estrada denota a presença de circulação de humanos no local. As residências do bairro Colina Verde distanciam-se da NG3 cerca de 100 metros. Ao analisar as características da NG3, no Quadro 3, foi verificado que a metade dos seus parâmetros macroscópicos pode melhorar o seu nível de qualidade (GP Razoável), desde que os órgãos públicos providenciem o cercamento e a proteção do local, impedindo a proximidade e a circulação de humanos, e evitando que sejam descartados os resíduos sólidos, consequentemente aumentando a preservação da NG3. A figura 3 (C) ilustra a Nascente Colina Verde (NG3) e a seta vermelha indica uma das três caixas em que era o ponto de captação da água.

Figura 3 - Nascentes (A) Parque Municipal Danilo Marques Moura - NG1, (B) Parque do Povo - NG2 e (C) Colina Verde - NG3
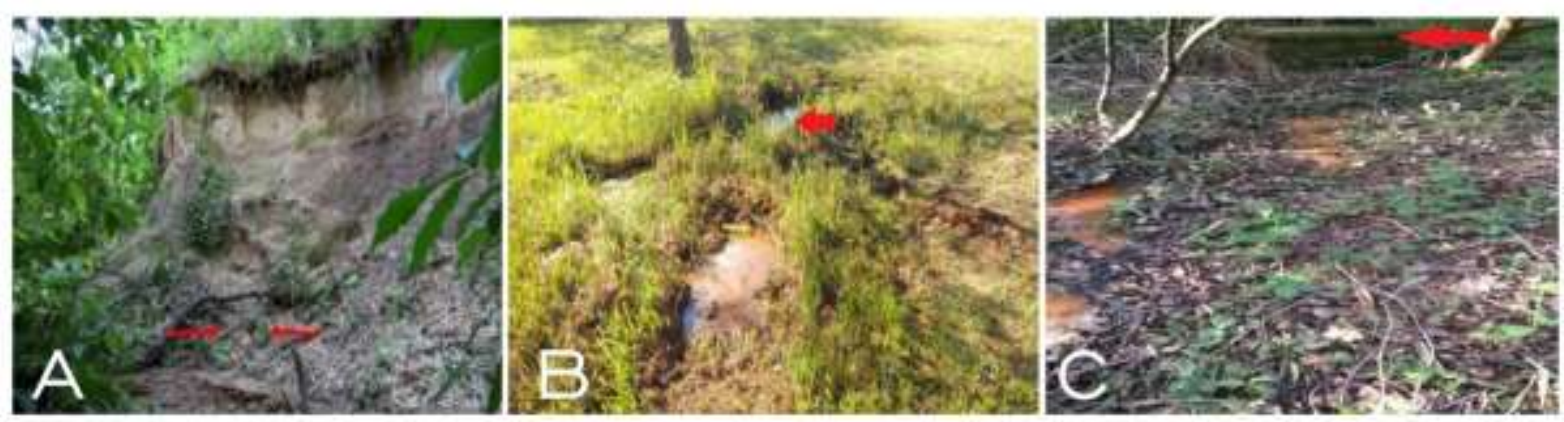

Autoria: Negri-Sakata (2017).

\section{Nascente Porto das Águas (NG4)}

A nascente Porto das Águas (NG4) está contida no Condomínio Porto das Águas, ainda sem construções residenciais, porém com infraestrutura urbana e está próxima à rodovia BR 272. Está localizada nas coordenadas geográficas: $24^{0} 11^{\prime} 02$ " Latitude $S, 53^{\circ}$ 00' 10" Longitude W e a 466 metros de altitude. A NG4 é do tipo perene, pontual, de depressão, e suas águas escoam para o Córrego São Paulo, que é afluente do Rio Água Branca. 
A água da NG4 apresenta-se transparente, sem cheiro, sem materiais flutuantes e com ausência de espuma, óleo e esgoto. No entanto, foram observados alguns resíduos sólidos (cadeira e garrafa, ambos de material plástico) no seu entorno. A NG4 é de fácil acesso tanto para animais domésticos quanto por humanos. A vegetação está em nível de baixa degradação, e não atende ao raio de 50 metros em seu entorno, conforme a Lei no 12.651/2012 (BRASIL, 2012). À sudeste do condomínio há uma residência privada a menos de 50 metros da NG4 e a sudoeste encontra-se a rodovia BR 272 a menos de 70 metros de distância, e o local sofre ação de fluxo superficial de água de chuva advinda da pavimentação asfáltica dessa rodovia.

Também foi observado um processo inicial erosivo no entorno da nascente, mas, segundo a administradora do condomínio, está sendo executada a recuperação das áreas afetadas e o plantio de árvores para a contenção do solo erodido. Ao analisar as características da NG4 no Quadro 3 foi averiguado que a metade dos seus parâmetros macroscópicos pode melhorar parcialmente o seu nível de qualidade (GP Razoável), desde que a administradora do condomínio providencie o cercamento e a proteção local, impedindo a proximidade e a circulação de humanos, animais domésticos e o descarte de resíduos sólidos, bem como executar o plantio de árvores num raio de 50 metros, conforme prescreve o Código Florestal Brasileiro Lei o 12.651/2012 (BRASIL, 2012). Porém há um agravante que pode dificultar a NG4 ser totalmente preservada, pois a menos de 50 metros da NG4 há uma residência privada, que deveria ser removida do local e é necessário reflorestar essa área e em direção à rodovia. Além disso, é necessário executar a drenagem da água da pavimentação asfáltica, impedindo que a mesma desça em direção a NG4. A execução dessas medidas pode contribuir com a sua preservação. A figura 4 (D) ilustra a Nascente Porto das Águas (NG4) e a seta vermelha indica o tubo de PVC por onde é drenada a água.

\section{Nascente Arroio Schimidt (NG5-A)}

A nascente do Arroio Schimidt (NG5-A) está protegida com estrutura de concreto e drenada até Arroio Schimidt. Essa canalização ocorreu no final da década de 1990. A região do arroio é considerada uma área de preservação permanente (APP) e está localizada entre os bairros Jardim Galileia e Jardim Curitiba. A NG5-A está localizada nas coordenadas geográficas: $24^{\circ} 10^{\prime} 43^{\prime \prime}$ Latitude S, 5301' 34" Longitude W, com 455 metros de altitude.

A água da NG5-A, apresenta-se transparente, sem odor, não há materiais flutuantes, espuma, óleo e esgoto. Em seu entorno há resíduos sólidos (mobília, podas de árvores, fezes de animais e materiais plásticos) e evidências de incineração de galhos, folhas de 
árvores e gramíneas. A vegetação é precária, não atendendo a Lei oㅜ 12.651/2012 (BRASIL, 2012), mas há uma reserva de mata nativa a menos de 100 metros de distância. De acordo com Nascimento (2005, p. 69) "Trata-se de um remanescente de pequenas proporções (em torno de um hectare) da floresta nativa, de forma retangular, parcialmente cercada por conjuntos habitacionais e confinado ao norte com um cemitério". As características da NG5A, analisadas no Quadro 3, informa o seu nível de qualidade (GP Ruim), que se deve em grande parte à falta de proteção local, pois a APP está protegida com dois fios de arame farpado frouxos e enferrujados, de fácil acesso à circulação de humanos, animais e ao descarte de resíduos sólidos. A cerca de 100 metros há residências, salão de eventos e rua sem pavimentação asfáltica e, por causa dessas proximidades, mais fácil o acesso e a exposição da NG5-A. Além disso, a falta de arborização na APP e a ampliação do terreno do cemitério nos últimos anos na direção da reserva nativa e em direção à APP têm impactado ainda mais a sua preservação. Portanto, para iniciar a recuperação do impacto ambiental da NG5-A, recomenda-se como medidas preventivas o cercamento da APP, o reflorestamento e a fiscalização contínua para evitar a presença de humanos e animais e o descarte de resíduos sólidos. A figura 4 (E) mostra as duas tubulações que escoam a água da Nascente Arroio Schimidt (NG5-A) para o Arroio Schimidt e setas vermelhas indicam as referidas tubulações.

\section{Nascente Jardim Galileia (NG5-B)}

A nascente do Jardim Galileia (NG5-B) localiza-se à margem oeste do Arroio Schimidt e está contida na APP próxima ao bairro Jardim Galileia. É uma nascente do tipo difusa, de depressão com acúmulo de água e parcialmente canalizada para o Arroio Schimidt. A NG5B encontra-se a cerca de 100 metros de distância da NG5-A e está localizada nas coordenadas geográficas: $24^{\circ} 10^{\prime} 45^{\prime \prime}$ Latitude S, $53^{\circ} 01^{\prime} 35^{\prime \prime}$ Longitude W e a 455 metros de altitude.

A água da NG5-B apresenta-se com a cor escura, forte odor, há resíduos sólidos (mobília, podas de árvores, fezes de animais, restos de construção e materiais plásticos) em seu entorno e materiais flutuantes (folhas), porém não foi observado espuma, óleo e esgoto. Com as características da NG5-B, analisadas no Quadro 3, foi averiguado que o seu nível de qualidade (GP Péssima) se deve a um conjunto de fatores associados que contribuem para a sua degradação, tais como a falta de proteção local, devido ao fácil acesso a circulação de humanos e animais, ao descarte de resíduos sólidos, à vegetação altamente degradada em desacordo com a Lei no 12.651/2012 (BRASIL, 2012) e à proximidade com as residências do bairro, aliados a outros parâmetros descritos na NG5-A. Esse local é propício à proliferação de mosquitos (Aedes aegypti) transmissores de doenças, devido à quantidade 
de resíduos sólidos descartados pela população local e ao acúmulo de água característico da nascente, além da precária canalização para o Arroio Schimidt. Portanto, para iniciar a recuperação do impacto ambiental da NG5-B, recomenda-se como medidas preventivas as mesmas citadas na NG5-A, com o acréscimo de adequação da canalização da água acumulada para o Arroio Schimidt. A figura 4 (F) ilustra o acúmulo de água próximo à Nascente Jardim Galileia (NG5-B).

Figura 4 - Nascentes (D) Porto das Águas - NG4, (E) Arroio Schimidt - NG5-A e (F) Jardim Galileia - NG5-B

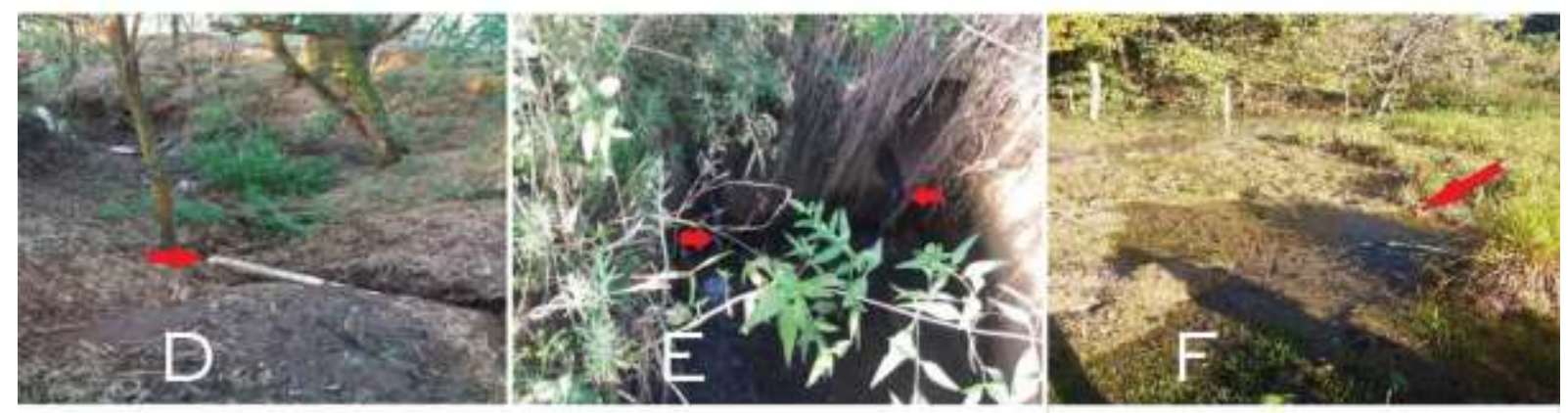

Autoria: Negri-Sakata (2017).

\section{Nascente Vila Guaíra (NG6)}

A nascente Vila Guaíra (NG6) está localizada no bairro Vila Guaíra e nas coordenadas geográficas: $24^{0} 11^{\prime} 07^{\prime \prime}$ Latitude $S, 53^{\circ} 02^{\prime}$ '02" Longitude W e a 428 metros de altitude. A NG6 é do tipo difusa, e qual foram localizados dois pontos de afloramento do lençol freático, a partir de duas áreas residenciais vizinhas e canalizadas pelos moradores por meio de dois tubos de PVC, sendo que um dos tubos atravessava um muro de concreto da área residencial para a APP e outro tubo de PVC passava sob o muro próximo à superfície do solo, em seguida as águas de ambos os tubos escoam superficialmente e deságuam no Arroio Schimidt. Nessa região da APP também há moradias habitacionais que se encontram em desacordo com a lei 12.651/2012 (BRASIL, 2012).

A água da NG6 apresentou-se transparente, com ausência de odor, espuma e óleo. Entretanto, foi percebida a presença de esgoto doméstico superficial e uma quantidade grande de resíduos sólidos diversos em seu entorno, e a vegetação estava ausente. Nas proximidades da NG6 havia a presença de animais e aves (equinos, cachorro e galinha), além de humanos. Com as características da NG6 analisadas no Quadro 3 foi averiguado que o seu nível de qualidade (GP Péssima) se deve em grande parte pela falta de proteção local, pois a APP é de fácil acesso à circulação de humanos, animais e ao descarte de resíduos sólidos, com a vegetação altamente degradada e a proximidade com as residências. Apesar dos pontos de afloramento da NG6 estarem no interior de quintais de 
duas residências e protegidas por caixa de concreto, está em desacordo com a medida provisória no 2.166-67/2001, artigo 3, pois essas áreas deveriam ser enquadradas como APP, devido à existência de nascente e não loteadas para moradias. Nessas condições ambientais a tendência é dificultar a preservação da NG6, podendo comprometer a qualidade de suas águas. Em Caldas Novas - GO, Biella e Costa (2006, p. 08) descrevem situação parecida à encontrada na NG6, onde as nascentes encontram-se dentro de terrenos "[...] mas estão praticamente dentro das residências, situados em zonas definidas como chácaras, quadras ou simplesmente área de invasão". A figura $5(G)$ evidencia a canalização por meio de tubo PVC da água da Nascente Vila Guaíra (NG6) de uma área residencial para a APP do Arroio Schimidt e a seta vermelha indica o tubo de PVC por onde é drenada a água.

\section{Nascente ASSEMUG (NG7)}

A nascente da ASSEMUG (NG7) está localizada na área da Associação dos Servidores Públicos Municipais de Goioerê no bairro Vila Guaíra e canalizada para formar três represas pequenas para fins paisagísticos, em seguida é drenada até o Arroio Schimidt. A NG6 está localizada nas coordenadas geográficas: $24^{\circ} 10^{\prime} 11^{\prime \prime}$ Latitude $S, 53^{\circ} 02^{\prime}$ ' $07^{\prime \prime}$ Longitude W e a 427 metros de altitude.

A água da NG7 apresentou-se transparente, sem odor, espuma, óleo e esgoto. Os materiais flutuantes observáveis foram plantas aquáticas "pingo d'água" e folhas sobre a superfície da água represada em tanques. A vegetação encontra-se em baixa degradação e estão presentes os resíduos sólidos (papeis e materiais plásticos) nas proximidades. A proteção da água na NG7 consiste de uma tela de alambrado de um metro de altura. No local há presença constante de humanos e animais domésticos, pois é uma área de lazer. $\mathrm{A}$ NG6 distancia-se a menos de 10 metros do salão de eventos e do campo de bocha, e a cerca de 20 metros da Avenida Tiradentes. Ao analisar as características da NG7 no Quadro 3 foi observado que o seu nível de qualidade (GP Razoável) pode melhorar parcialmente, desde que se evite o descarte de resíduos sólidos, presença de animais domésticos e haja maior proteção local e constante manutenção dos vegetais aquáticos presentes no tanque de represamento da água. No entanto, a existência de benfeitorias construídas para o lazer da referida associação e a rua no entorno da NG7 impede, atualmente, quaisquer tentativas de ter a APP em situação ambiental condizente com a sua necessária preservação. A figura 5 (H) mostra a Nascente ASSEMUG (NG7) e a seta vermelha indica os tubos de PVC nos quais a água da NG7 é drenada. 


\section{Nascente Jardim Bela Vista (NG8)}

A nascente Jardim Bela Vista (NG8) encontra-se em uma zona suburbana, limítrofe entre o bairro Jardim Bela Vista e área rural privada. A água da NG8 escoa para o córrego "sem nominação", que é afluente do Rio Água Branca. Está localizada nas coordenadas geográficas: $24^{0} 10^{\prime} 29^{\prime \prime}$ Latitude $S, 53^{\circ} 02^{\prime} 16^{\prime \prime}$ Longitude W e a 429 metros de altitude.

A água da NG8 apresenta-se com a cor clara e ausência de odor, óleo e esgoto, porém havia espuma e materiais flutuantes proveniente das plantas locais e folhas em decomposição. Além disso, continha ao redor resíduos sólidos (materiais plásticos, fezes de animais, pneus e papel). Foi encontrado um equino pastando próximo a NG8, o qual também fez uso dessa água, devido à ausência de proteção nesse local. Na área em seu entorno havia um processo erosivo de pequena extensão e a vegetação apresenta-se em nível de alta degradação. A área é protegida com cerca de arame, porém de fácil acesso por humanos, pois a NG8 encontra-se a menos de 50 metros de ruas e residências do bairro Jardim Bela Vista. As características da NG8, analisadas no Quadro 3, mostram que o seu nível de qualidade (GP Péssima) se deve em grande parte pela falta de proteção local adequada, pois a área é cercada com arame de metal flexível, sendo de fácil acesso à circulação de humanos, animais e ao descarte de resíduos sólidos. A vegetação altamente degradada, em desacordo com a Lei № 12.651/2012 (BRASIL, 2012) contribui com o desenvolvimento do processo erosivo do solo, podendo aumentar a degradação da área se não houver o reflorestamento para sua contenção. Também a proximidade com as residências do bairro favorece a circulação de moradores da localidade, dificultando a sua preservação. A figura 5 (I) apresenta a nascente Jardim Bela Vista (NG8) e a seta vermelha indica o ponto de afloramento da água centrada num pneu velho.

Figura 5 - Nascentes (G) Vila Guaíra - NG6, (H) ASSEMUG - NG7 e (I) Jardim Bela Vista NG8

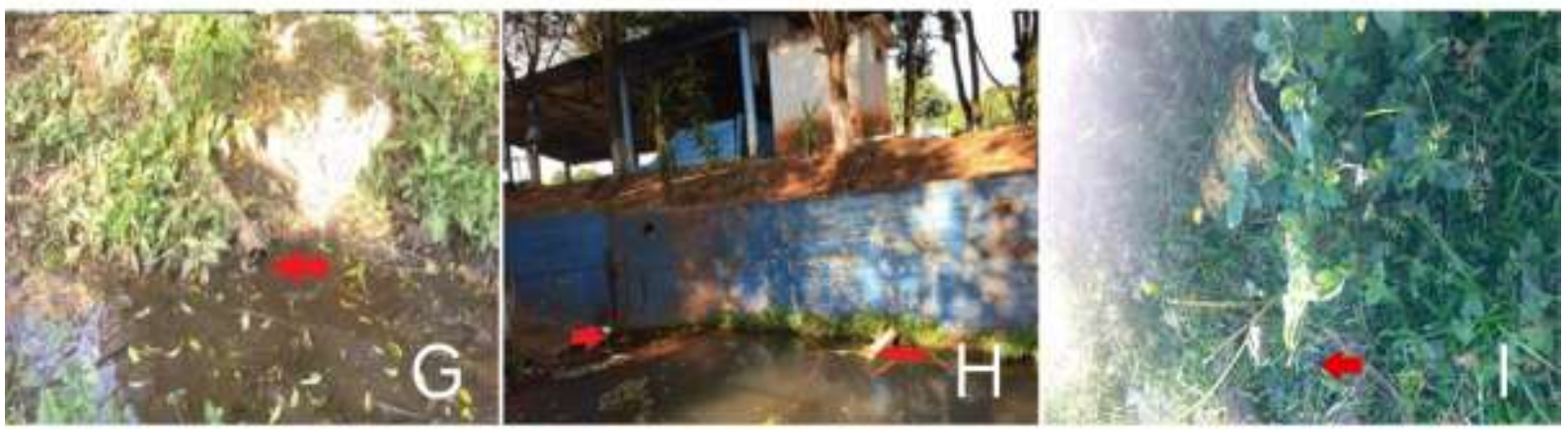

Autoria: Negri-Sakata (2017). 
O Quadro 3 apresenta os níveis de qualidade das características macroscópicas das nascentes diagnosticadas. Dos parâmetros macroscópicos analisados no Quadro 3 verificou-se situações que provocam impactos ambientais às nascentes e torna-se evidente a necessidade de providenciar algumas medidas específicas para melhorar a situação de cada nascente investigada.

Quadro 3 - Nível de Qualidade Ambiental relativos aos aspectos macroscópicos das nascentes urbanas de Goioerê-PR

\begin{tabular}{|c|c|c|c|c|c|c|c|c|c|}
\hline CARACTERÍSTICAS & NG1 & NG2 & NG3 & NG4 & $\begin{array}{l}\text { NG5 } \\
\text { (A) }\end{array}$ & $\begin{array}{l}\text { NG5 } \\
\text { (B) }\end{array}$ & NG6 & NG7 & NG8 \\
\hline Cor da água & 2 & 2 & 2 & 3 & 3 & 1 & 2 & 3 & 2 \\
\hline Odor & 3 & 3 & 3 & 3 & 3 & 1 & 3 & 3 & 3 \\
\hline Resíduos sólidos ao redor & 3 & 2 & 1 & 2 & 1 & 1 & 1 & 2 & 2 \\
\hline Materiais flutuantes & 3 & 2 & 3 & 3 & 3 & 2 & 3 & 3 & 2 \\
\hline Espumas & 3 & 3 & 3 & 3 & 3 & 3 & 3 & 3 & 2 \\
\hline Óleo & 3 & 3 & 3 & 3 & 3 & 3 & 3 & 3 & 3 \\
\hline Esgoto & 3 & 3 & 3 & 3 & 3 & 3 & 2 & 3 & 3 \\
\hline Vegetação & 2 & 1 & 2 & 2 & 1 & 1 & 1 & 2 & 1 \\
\hline Uso por animais & 3 & 1 & 3 & 2 & 1 & 1 & 1 & 2 & 1 \\
\hline Uso por humanos & 3 & 1 & 2 & 2 & 1 & 1 & 1 & 1 & 1 \\
\hline Proteção do local & 1 & 1 & 1 & 3 & 2 & 1 & 1 & 2 & 1 \\
\hline $\begin{array}{l}\text { Proximidade residencial } \\
\text { ou estabelecimento }\end{array}$ & 3 & 2 & 2 & 1 & 1 & 2 & 1 & 1 & 1 \\
\hline Tipo de área de inserção & 3 & 3 & 3 & 1 & 3 & 3 & 3 & 3 & 1 \\
\hline Pontuação & 35 & 28 & 31 & 31 & 28 & 23 & 25 & 31 & 23 \\
\hline Nível de Qualidade & ర్రి & $\frac{\xi}{\overline{\widetilde{x}}}$ & 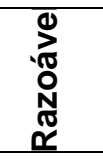 & 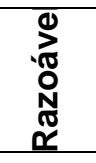 & $\frac{\boldsymbol{g}}{\bar{z}}$ & 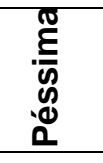 & 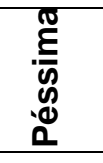 & 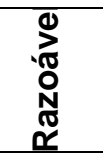 & 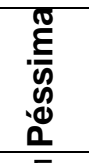 \\
\hline Classe & B & $\mathrm{D}$ & C & C & $\mathrm{D}$ & $E$ & $E$ & C & $E$ \\
\hline
\end{tabular}

Organizado por: Negri-Sakata (2018).

Quanto à cor da água, apenas a da NG5-B apresentou-se com cor escura e em outras quatro a cor clara. A alteração na cor da água se deve pela decomposição de matéria orgânica e sedimentos do solo local. Resíduos sólidos ao redor das nascentes somente estavam ausentes na NG1, por estar inserida na UC, o que dificulta a presença ou circulação constante de humanos, já em outras nascentes a falta de proteção satisfatória favorece a presença de resíduos sólidos. Os materiais flutuantes que foram encontrados em três nascentes são provenientes de plantas ou folhas no entorno, o que não é tão prejudicial se comparado a óleo e espuma, os quais não foram observados no período da coleta de dados. 
Em todas as nascentes investigadas havia algum tipo de irregularidade na vegetação, algo que não atendia à Lei do Código Florestal, fato esse devido ao uso irregular do solo e urbanização. O uso por animais e humanos foi constatado em muitas nascentes, sendo maior quando não há proteção adequada. A proteção do local foi verificada em algumas nascentes, porém insatisfatória para a sua preservação. A proximidade de residências ou estabelecimentos foi observada em várias nascentes e, quanto mais próxima de residências estava a nascente, maior era o impacto (GOMES; MELO; VALE, 2005), fato esse oriundo da ocupação desordenada do solo urbano. Quanto à área de inserção, foi constatada duas em "áreas privadas" e sete em "áreas públicas", verificando-se que as de áreas públicas se encontravam em situação de abandono, enquanto que, nas de propriedades particulares, uma estava sendo utilizada para fins paisagísticos, sem levar em consideração a sua verdadeira função e a outra estava em situação de total abandono.

Outro problema que foi encontrado em algumas nascentes urbanas de Goioerê é o processo erosivo, apesar de não estar contido na tabela de IIAN. Carvalho (2004) alerta que o solo sem proteção da cobertura vegetal pode ficar endurecido pela ação das gotas da chuva, o que irá reduzir a velocidade e a quantidade de infiltração da água, além de favorecer as enxurradas. Segundo Magalhães (2001, p. 5) "[...] a erosão urbana no Brasil distingue-se das formas de erosões naturais e suas derivadas rurais por novos condicionantes, seus mecanismos exclusivos, os grandes volumes de materiais envolvidos e o papel representado pelo assoreamento", além de se verificar o incremento relativo e absoluto de lixo, entulho, matéria orgânica e resíduos industriais.

Portanto, foi diagnosticado que, nas nascentes estudadas na área urbana de Goioerê, nenhuma foi considerada dentro do Índice de Impacto Ambiental de Nascentes (IIAN) na Classe A e Grau de Preservação (GP), Ótima. Uma foi classificada como B e GP Boa. Três situaram-se na Classe C, GP Razoável, duas Classe D, GP Ruim. E três foram consideradas na Classe E, GP Péssima, conforme é demonstrada na figura 6.

Os resultados obtidos do diagnóstico ambiental demonstram que as nascentes da área urbana de Goioerê estão esquecidas ou alteradas para atender uma necessidade específica, descaracterizando-as de sua real funcionalidade.

Os fatores antrópicos que causam impactos ambientais às nascentes são comuns em áreas urbanizadas no Brasil, pois diversos estudos realizados sobre as nascentes urbanas relataram problemas parecidos com o diagnosticado em Goioerê (GOMES; MELO; VALE, 2005; BIELLA; COSTA, 2006; CARVALHO; ARAÚJO, 2007; VIEIRA NETO; FASSINA; PRATTE-SANTOS, 2012; NECKEL, 2013), e outros. Esses fatores são decorrentes do processo de urbanização desordenada, no qual os interesses privados e o desconhecimento ambiental prevaleceram sem levar em consideração a sustentabilidade. 
Figura 6 - Classificação das nascentes urbanas de Goioerê, segundo o IIAN e o Grau de Preservação

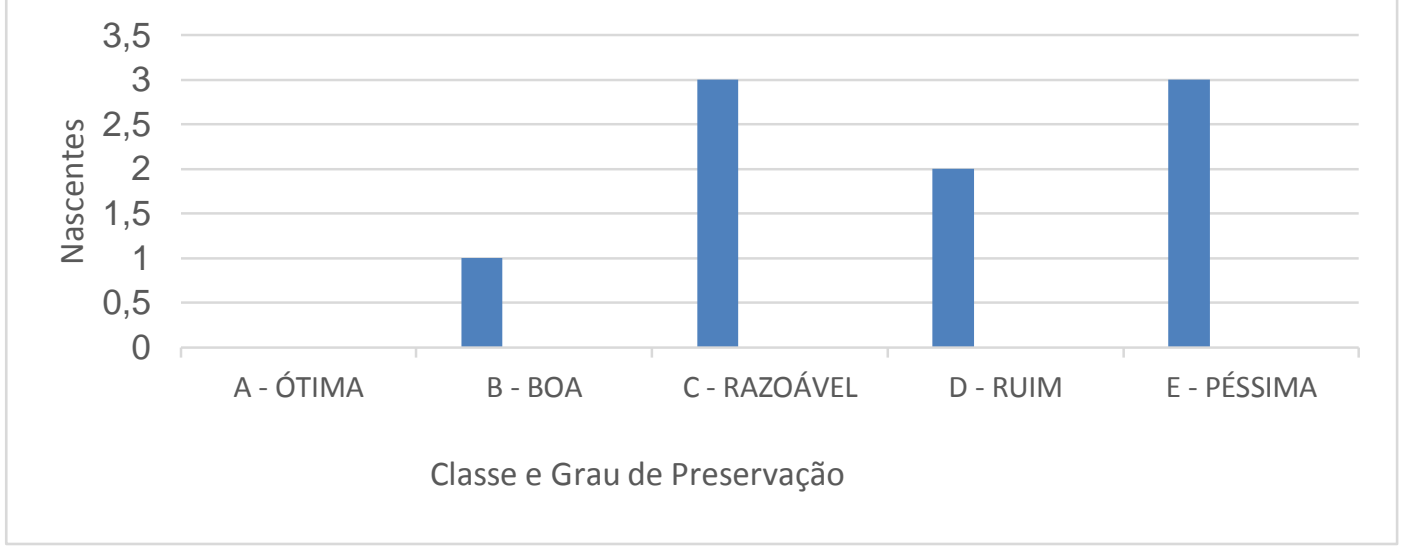

Organizado por: Negri-Sakata (2017).

De acordo com Sepe; Pereira e Bellenzani (2014) o avanço do novo Código Florestal e a forma explicita da redação do artigo $4^{\circ}$ deixa clara a existência de áreas de preservação permanente em áreas urbanas. Todavia, mesmo que esta redação explicite, por outro lado, também se torna genérica demais, não favorecendo sua adequação para as diversas realidades das cidades brasileiras ou mesmo para as distintas realidades intra-urbanas existentes nas grandes metrópoles, exemplificando com o caso de São Paulo como o mais emblemático.

Em Cuiabá-MT, Jesus e Santos (2015) apontam que há a presença de alguns empreendimentos imobiliários horizontais e verticais na área de uma nascente. Mas o que denota maior preocupação são suas localizações, que essencialmente estão sobre as áreas mais a montante da nascente, provocando o aterramento de alguns olhos d'águas.

Assim, constatou-se que as nascentes urbanas da cidade de Goioerê-PR estão sofrendo impacto ambiental em desconformidade com a legislação ambiental, sendo que a presença de resíduos sólidos, insuficiência e ausência de vegetação, uso por animais, uso por humanos, local desprotegido e proximidade a residências e estabelecimentos são os problemas mais comuns.

\section{CONSIDERAÇÕES FINAIS}

As nascentes urbanas de Goioerê-PR investigadas, que se encontram em desconformidade com as leis ambientais brasileiras, estão em situação de vulnerabilidade ambiental, necessitando intervenção pública para a sua recuperação.

Há a necessidade de trabalho de sensibilização ambiental à população, a fim de divulgar e orientar atitudes corretas para a manutenção deste ambiente e que no plano 
diretor da cidade seja priorizada a manutenção de um ambiente sustentável, não cedendo à especulação imobiliária.

Para ampliar o estudo sobre as nascentes urbanas de Goioerê é fundamental a realização de outras pesquisas que considerem outros períodos de coleta de dados, 0 sistema econômico, social e cultural, também análises físico-químicas da água de cada nascente, pois pesquisas ambientais requerem estudos complexos e interdisciplinares. Portanto, são necessárias futuras investigações para conhecer melhor os potenciais hídricos disponíveis na zona urbana e como preservá-los para as futuras gerações.

\section{REFERÊNCIAS}

ÁGUASPARANÁ. Instituto das Águas do Paraná. Índice de precipitação pluviométrica. Disponível em: <http://www.aguasparana.pr.gov.br/modules/conteudo/conteudo.php?conteudo=264 2 . Acesso em: 5 jun. 2017.

ANA. Agência Nacional de Águas. Ciclo hidrológico e águas subterrâneas. 2014. Disponível em: <http://arquivos.ana.gov.br/institucional/sge/CEDOC/Catalogo/2014/CicloHidrologicoeAguas Subterraneas2014.pdf $\geq$. Acesso em: 20 jan. 2018.

ANA. Agência Nacional de Águas. Lei das águas: política nacional dos recursos hídricos: fundamentos, objetivos e diretrizes. Capacitação para gestão das águas, módulo 1. Disponível em: <https://capacitacao.ead.unesp.br/dspace/bitstream/ana/121/3/ANA_OS11_Mod1_Unid123_ V1.1.pdf>. Acesso em: 27 dez. 2017.

ANA. Agência Nacional de Águas. Programa produtor de água. 2012. Disponível em: $<$ http://produtordeagua.ana.gov.br/>. Acesso em: 27 jan. 2018.

BIELLA, C. A.; COSTA, R. A. Análise da qualidade ambiental das nascentes urbanas de Caldas Novas - GO. In: SIMPÓSIO NACIONAL DE GEOMORFOLOGIA/REGIONAL CONFERENCE OF GEOMORPHOLOGY, 6., 2006, Goiânia. Anais... Goiânia: UFG, 2006. Disponível em: <http://lsie.unb.br/ugb/sinageo/6/4/148.pdf>. Acesso: 29 jul. 2018.

BRASIL. Câmara dos Deputados. Lei № 4.771 de 15 de setembro de 1965. Institui o novo Código Florestal. Disponível em: <http://www2.camara.leg.br/legin/fed/lei/1960-1969/lei4771-15-setembro-1965-369026-publicacaooriginal-1-pl.htm>. Acesso em: 5 jul. 2017.

BRASIL. Lei no 12.651, de 25 de maio de 2012. Novo Código Florestal. Dispõe sobre a proteção da vegetação nativa, 2012. Disponível em: <http://www.planalto.

gov.br/ccivil_03/_Ato2011-2014/2012/Lei/L12651.htm>. Acesso em: 21 maio 2017.

BRASIL. Lei no 9.433, de 8 de janeiro de 1997. Institui a Política Nacional de Recursos Hídricos, cria o Sistema Nacional de Gerenciamento de Recursos Hídricos... Disponível em: <http://www.planalto.gov.br/ccivil_03/leis/L9433.htm>. Acesso em: 3 jun. 2017.

BRASIL. Ministério do Meio Ambiente. Conselho Nacional do Meio Ambiente.

Resolução Conama no 429, de 28 de fevereiro de 2011. Dispõe sobre a metodologia de recuperação das Áreas de Preservação Permanente - APPs. Disponível em: <http://www.mma.gov.br/port/conama/legiabre.cfm?codlegi=644>. Acesso em: 2 maio 2017. 
BRASIL. Ministério do Meio Ambiente. Conselho Nacional do Meio Ambiente. Resolução Conama № 001, de 23 de janeiro de 1986. Dispõe sobre critérios básicos e diretrizes gerais para a avaliação de impacto ambiental. Disponível em: <http://www.mma.gov.br/port/conama/legislacao/CONAMA_RES_CONS_1986_001.pdf>. Acesso em: 07 jul. 2018.

BRASIL. Ministério do Meio Ambiente. Programa plantadores de rios. 2017. Disponível em: <http://www.brasil.gov.br/meio-ambiente/2017/06/programa-plantadores-de-rios-vaiincentivar-a-populacao-a-preservar-nascentes>. Acesso em: 27 jan. 2018.

CARARD, R. F. Identificação e análise da degradação ambiental no Parque Ecológico Municipal Danilo Marques Moura em Goioerê - PR. 2016. Trabalho de Conclusão de Curso (Graduação em Engenharia Ambiental) - Departamento Acadêmico Ambiental, Universidade Tecnológica Federal do Paraná, Campo Mourão.

CARVALHO, J. Q. G.; ARAÚJO, R. N. Algumas considerações sobre os impactos na nascente do Igarapé Caranã. Acta Geográfica, Boa Vista-RR, v. 1, n. 1, p. 95-103, 2007.

CARVALHO, S. L. Medidas que preservam nascentes e mananciais. Jornal Sem Limites, Castilho, SP, 1 jul. 2004. Disponível em:

<http://www.feis.unesp.br/irrigacao/jsl01072004.php>. Acesso em: 23 maio 2017.

FELIPPE, M. F. Caracterização e tipologia de nascentes em unidades de conservação de Belo Horizonte - MG com base em variáveis geomorfológicas, hidrológicas e ambientais. 2009. Dissertação (Mestrado em Geografia) - Departamento de Geografia, Universidade Federal de Minas Gerais, Belo Horizonte.

GOMES, P. M.; MELO, C.; VALE, V. S. Avaliação dos impactos ambientais em nascentes na cidade de Uberlândia/MG: análise macroscópica. Revista Sociedade \& Natureza, Uberlândia, MG, v. 17, n. 32, p. 103-120, 2005.

HIRATA, R.; ZOBY, J. L. G.; OLIVEIRA, F. R. Água subterrânea: reserva estratégica ou emergencial. In: BICUDO, C. E. M.; TUNDISI, J. G.; SCHEUENSTUHL, M. C. B. (Org.). Águas doces do Brasil: análises estratégicas. São Paulo: Instituto de Botânica, 2010. p. $149-161$.

IBGE. População estimada em 2017. Disponível em:

<https://cidades.ibge.gov.br/v4/brasil/pr/goioere/panorama>. Acesso em: 29 maio 2017.

INSTITUTO PARANAENSE DE DESENVOLVIMENTO ECONÔMICO E SOCIAL-IPARDES. Caderno estatístico do Município de Goioerê. Disponível em:

<http://www.ipardes.gov.br/cadernos/MontaCadPdf1.php?Municipio=87360>. Acesso em: 1 jun. 2017.

JESUS, C. R.; SANTOS, A. J. C. Problemática sócioambiental urbana da nascente do Córrego Vassoral em Cuiabá - MT. Geographia Opportuno Tempore, Londrina, v. 2, n. 1, p. 93-113, jan. /jul. 2015.

MAGALHÃES, R. A. Erosão: definições, tipos e formas de controle. In: SIMPÓSIO NACIONAL DE CONTROLE DE EROSÃO, 7., 2001, Goiânia. Anais... Goiânia: ABGE, 2001. p. 1-11.

NASCIMENTO, P. B. Análise ambiental do Arroio Schimidt - Goioerê - PR. 2005.

Dissertação (Mestrado em Geografia) - Departamento de Geografia, Universidade Estadual de Maringá, PR, Maringá.

NECKEL, A. Proposta para a recuperação ambiental das nascentes e da área verde do loteamento Cidade Universitária, no município de Passo Fundo/RS. Para Onde!? Porto Alegre, RS, v. 7, n. 1, p. 10-16, 2013.

PARANÁ. Secretaria de Estado do Meio Ambiente e Recursos Hídricos - SEMA. Nascentes protegidas e recuperadas. Curitiba, 2010. Disponível em: 
<http://www.meioambiente.pr.gov.br/arquivos/File/corh/Cartilha_nascentesprotegidas.pdf>. Acesso em: 2 jun. 2017.

PORTO-GONÇALVES, C. W. A luta pela apropriação e reapropriação social da água na América Latina. In: FERNANDES, B. M. Campesinato e agronegócio na América Latina: a questão agrária atual. São Paulo: Expressão Popular, 2007. p. 195-221.

ROGERS, P. P.; LLAMAS, M. R.; MARTÍNEZ-CORTINA, L. Water crisis: myth or reality? Londres: Taylor \& Francis, 2006.

SEPE, P. M.; PEREIRA, H. M. S. B.; BELLENZANI, M. L. O novo Código Florestal e sua aplicação em áreas urbanas: uma tentativa de superação de conflitos? In: SEMINÁRIO NACIONAL SOBRE O TRATAMENTO DE ÁREAS DE PRESERVAÇÃO PERMANENTE EM MEIO URBANO E RESTRIÇÕES AMBIENTAIS AO PARCELAMENTO DO SOLO, 3., 2014, Belém, PA. Anais eletrônicos... Belém: UFPA, 2014. p. 45. Disponível em:

$<$ http://anpur.org.br/app-urbana-2014/anais/ARQUIVOS/GT2-243-120-

20140710190757.pdf>. Acesso em: 25 nov. 2017.

SERVIÇO NACIONAL DE APRENDIZAGEM RURAL-SENAR. Programa especial de proteção de nascentes. Disponível em: <http://www.senar.org.br/programa/programaespecial-protecao-de-nascentes>. Acesso em: 27 jan. 2018.

TUCCI, C. E. M. Urbanização e recursos hídricos. In: BICUDO, C. E. M.; TUNDISI, J. G.; SCHEUENSTUHL, M. C. B. (Org.). Águas doces do Brasil: análises estratégicas. São Paulo: Instituto de Botânica, 2010. p. 112 - 128.

VIEIRA NETO, O. V.; FASSINA, G. C.; PRATTE-SANTOS, R. Estado de conservação das nascentes urbanas do município de Vila Velha, ES. Natureza on line, Santa Teresa, ES, v. 10, n. 2, p. 85-88, 2012. Disponível em:

<http://www.naturezaonline.com.br/natureza/conteudo/default.asp?volume=10\&numero=2>. Acesso em: 29 jul. 2018.

WINCANDER, R.; MOROE, J. S. Fundamentos de geologia. São Paulo: Cengage Learning, 2011.

YAMATO, N. M.; PARMA, T. R.; SCHUTZER, J. G. A preservação de nascentes em área de urbanização consolidada: microáreas de proteção ambiental como instrumento urbanístico para um zoneamento ambiental do solo urbano. In: SEMINÁRIO NACIONAL SOBRE O TRATAMENTO DE ÁREAS DE PRESERVAÇÃO PERMANENTE EM MEIO URBANO E RESTRIÇÕES AMBIENTAIS AO PARCELAMENTO DO SOLO, 3., 2014, Belém, PA. Anais eletrônicos... Belém: UFPA, 2014. p. 61. Disponível em: <http://anpur.org.br/app-urbana2014/anais/ARQUIVOS/GT4-163-25-20140517111642.pdf>. Acesso em: 25 nov. 2017.

Recebido: fevereiro de 2018. Aceito: agosto de 2018. 